REFERENCIAÇ̃̃O: UM ESTUDO DE ASPECTOS DA ORALIDADE NO DISCURSO LITERÁRIO*

VÂNia Maria Lescano GUERRA**

RESUMo

Nosso estudo sobre a linguagem oral envolvida nos propósitos da interação, via discurso literário, vem rediscutir a utilização que o locutor faz dos processos de categorizar (e recategorizar), para manipulação da direção do enunciado, a partir do pressuposto de que o processo de referenciação constitui uma atividade discursiva.

Palavras-chave: Referência, produção textual, literatura, linguagem oral.

\title{
CONSIDERAÇÕES INTRODUTÓRIAS
}

Do ponto de vista lingüístico, os quadros teóricos dentro dos quais se pode desenvolver um estudo da referenciação são vários. Acreditase, no entanto, que os modelos funcionalistas - que consideram que referenciar, no processo da língua em uso, envolve interação e, conseqüentemente, intenção - permitem uma investigação privilegiada dessa categoria. Argumenta-se, segundo esse modelo, que falar de referenciação, na língua em função, exige desligar-se da concepção de que os locutores simplesmente escolhem os referentes segundo as noções de mundo que esses referentes evocam, numa categorização cognitiva que está disponível fora e antes da atividade discursiva.

* Trabalho apresentado no XIX ENANPOLL, 20 anos de ANPOLL, no GT Descrição do Português, Maceió, AL, julho de 2004.

** Doutora pela Unesp de Araraquara e docente do Programa de Mestrado em Letras, Campus de Três Lagoas, Universidade Federal de Mato Grosso do Sul.

E-mail:vguerra1@terra.com.br 
Como as reflexões sobre o estudo das estratégias de referenciação na linguagem oral são ainda escassas, procuramos desenvolver aqui alguns elementos teóricos fundamentados no princípio de que todas as nossas atividades, sejam lingüísticas ou não, são sempre situadas, seja do ponto de vista social, cognitivo ou histórico. Elas são também interacionais e não dependem apenas de imposições ou restrições externas. Dessa forma, acreditamos que a língua não seja apenas um simples sistema de representações semânticas ou configurações de um mundo objetivo, ou um sistema de comunicação transparente, autônomo e homogêneo.

A partir da visão da língua em funcionamento, o processo de referenciação não se reduz à identificação de objetos da realidade, mas diz respeito à própria constituição do texto em que uma rede de referentes são introduzidos como objetos de discurso (ApothéLOz e ReICHLERBÉGUELIN, 1995), e como tais permanecem, de acordo com certas estratégias dependentes da formulação textual.

Todas as reflexões aqui realizadas baseiam-se no pressuposto de que a língua é um domínio público de construção simbólica e interativa, oportunizando, na convivência cooperativa, a própria sobrevivência da espécie humana.

Sob esses aspectos, analisamos como o discurso literário constrói seus mundos a partir da linguagem oral. Para isso, escolhemos o romance O coronel e o lobisomem, em que o discurso-narrador se apresenta multifacetado pela condensação de papéis que o cindem, o que permite o encadeamento de elementos favoráveis à hipótese de que as marcas de subjetividade, que o discurso de Ponciano ${ }^{1}$ produz, atestam uma natureza múltipla que o torna, ao mesmo tempo, meio (porque dividido em suas funções) e duplo (porque multiplicado em seus papéis).

Disso resulta a construção de mundos pelo discurso literário, mundos esses surgidos de um acordo tácito suposto pelo locutor na sua relação com o interlocutor e seus valores. Nitidamente, a referenciação observada na teia do texto, nas filigranas ${ }^{2}$ do discurso oral, se liga a um jogo entre entidades definidas e entidades indefinidas, jogo que os 
interlocutores manipulam dentro da negociação em que se constitui o estabelecimento do universo discursivo.

É certo que toda enunciação é socialmente dirigida, mesmo nos casos em que não se trate de uma informação factual, mas da expressão de uma necessidade qualquer. Ademais qualquer palavra se compõe de duas faces: é determinada não apenas pelo fato de proceder de alguém, mas também por se dirigir ao outro (BAKHTIN, 1988). A enunciação é um acontecimento que necessariamente pressupõe não apenas a mobilização dos protagonistas da interação da linguagem, mas também uma ancoragem espacial e temporal. Isso quer dizer que, além de supor a presença de um locutor e de um alocutário, ela pressupõe o espaço e o tempo em que os interactantes estão inseridos (BENVENISTE, 1989).

Desse contexto podemos extrair ainda uma sócio-pragmática com especificações cognitivas, ao postularmos que entre os interlocutores e o mundo se verifica uma relação complexa de elaboração da realidade. Isso se torna crucial no momento de analisarmos a construção do processo referencial na linguagem falada, objeto deste estudo.

\section{A REFERENCIAÇÃo NO DISCURSO LITERÁRIO}

Referenciar, no processo da língua em uso, envolve interação e intenção: os participantes de um discurso negociam o universo de discurso de que falam, e, dentro dele, num dado momento, escolhem referir-se a algum (alguns) indivíduo(s) cuja identidade estabelecem (ou não) segundo queiram (ou não) garantir a sua existência nesse universo. Para efeitos operacionais, podemos designar como referência, em sentido amplo, todo esse processo, e reservar preferentemente o termo referenciação para quando mais especificamente se estiver falando da construção discursiva, da constituição textual, a saber, da formação da rede referencial (NEVEs, 2000).

A referência é tradicionalmente definida como uma relação que se mantém entre uma expressão e o que ela significa em ocasiões 
particulares do discurso (Lyons, 1977, p. 174). Em uma oração declarativa como

De noite, até o turvar do sono, a gente batia carta. (Ex. 1, p. 92 de $O$ coronel e o lobisomem) ${ }^{3}$

o locutor se refere a determinada(s) pessoa(s) por meio de uma expressão referencial (a gente $=$ nós). Se a referência é bem sucedida - o que se liga ao uso apropriado da expressão referencial pelo falante - o interlocutor identificará corretamente o(s) referente(s).

Nessa concepção de relação referencial, é a expressão (usada naquela ocasião particular e sob condições relevantes) que faz referência a seu referente, mas é o locutor, na verdade, que faz referência, já que, no ato de referir-se, ele usa a expressão referencial. Assim, nesse modo de ver, quem investiga a que se refere uma expressão " $x$ " está investigando a que locutor se refere quando usa a expressão " $x$ ".

Uma referenciação textual é bem sucedida quando o interlocutor consegue identificar o referente do discurso no ponto em que essa operação lhe é solicitada, e tal identificação ocorre quando o locutor a deixou acessível. Isso configura duas propriedades da referencialidade no discurso, a identificabilidade e a acessibilidade, ambas ligadas à distribuição de informação, dependentes do contínuo em que se distribuem o dado e o novo no discurso. Como aponta Chafe (1996), ambas as categorias implicam inferência, mas a acessibilidade requer uma espécie mais direta e imediata de inferência, porque não se limita a pessoas, objetos e abstrações, mas estende-se a eventos e estados.

Segundo o autor, são componentes da identificabilidade: a) o julgamento, pelo locutor, de que o conhecimento do referente a que se remete já é compartilhado (direta ou indiretamente) com o interlocutor; b) a escolha, pelo locutor, de uma linguagem com tal rigor de categorização que todos os referentes compartilhados por ele e pelo interlocutor se reduzam ao que está em questão; c) o julgamento, pelo locutor, de que esse referente particular é o exemplar mais saliente da categoria, dentro daquele contexto. 
Com Apothéloz e Reichler-Béguelin (1995), pode-se dizer que a categorização lexical vem a ser o reflexo ou a conseqüência, na verdade o ponto final de uma evolução do aspecto sob o qual o objeto é encarado, isto é, a categorização representa o ponto de vista do locutor naquele determinado momento da construção do discurso. É o que se vê, na denominação os compadres (Quintanilha e Dona Alvarina) nessa passagem do romance já mencionado:

Quintanilha, pouco mais atrás de Dona Alvarina, não cabia na botina inaugurada. De fingimento, como manda a cortesia, mostrei espanto:

- Pelos vistos, os compadres vão para festa de batizado. (Ex. 2, p. 72)

Para nós, inseridos na concepção de linguagem como atividade sócio-cognitiva em que a interação, a cultura, a experiência e os aspectos situacionais interferem na determinação referencial, duas pessoas sabem que falam da mesma coisa, ou sabem como conduzir um mesmo tópico não porque usam o mesmo item lexical, nem porque as coisas estão previamente prontas, mas porque negociam sentidos e partilham formas de ver o mundo. Nessa direção, a coerência pode ser um ponto de vista dos interlocutores, isto é, constituir-se como o resultado das operações de progressão referencial (estratégias de designação de referentes que formam a cadeia referencial) e de progressão tópica (assuntos ou tópicos discursivos tratados ao longo do texto). Referenciação e coerência surgem como aspectos centrais da produção de sentido no texto, contribuindo para a organização tópica que, embora se interpenetrem, são duas noções diferentes (MARCuSCHI, 2003).

Nessa perspectiva, o texto é visto como evento, acontecimento e sua existência depende de que alguém o processe em algum contexto. Isso porque na operação com a língua, lidamos mais do que com um simples uso de regras, sejam elas de seqüenciação ou outras. Podemos dizer que o texto é visto como lugar de interação epistemológica dos seres humanos com o mundo da experiência, o local da construção da própria experiência. 
Quando deslocamos os referentes para as práticas discursivas e os transformamos em objetos de discurso, deparamo-nos com a instabilidade constitutiva não só das categorias cognitivas, mas também das categorias lingüísticas (Mondada \& Dubois, 1995). Os objetos do mundo não possuem características "essenciais", "intrínsecas" e "inerentes", que se mantenham mesmo quando sofrem alterações materiais. Ao contrário, o mundo e seus objetos caracterizam-se pela instabilidade, o que repercute sobre as atividades nomeadoras dos usuários das línguas naturais. Muitas vezes, o que é considerado como "dificuldade de nomear", como "erro" dos falantes, não é outra coisa que não a marca dessa instabilidade no mundo.

Posto isso, é possível concluir que é ilusória a concepção de que há uma correspondência exata e necessária entre as palavras e as coisas: de que as coisas do mundo nos são dadas a priori, ou estabelecidas independentemente de nossa percepção. Ao lado disso, sabemos que é impossível alguém se expressar lingüisticamente a não ser por algum gênero textual. Todo texto sempre se dá concretamente em sua materialidade em algum gênero. Notamos que os diferentes gêneros textuais constituem também diferentes modos de organizar e conduzir os referentes. Daí a relevância da abordagem dessas questões num estudo que pretende dar conta das formas peculiares do processamento textual-discursivo da língua falada no bojo do discurso literário, em que o texto surge como um universo de relações seqüenciadas, mas não-lineares.

Adotando os pressupostos teóricos dos estudiosos mencionados, consideramos também algumas posições defendidas por Whiteside (1987) sobre a referenciação no texto literário. Para esse autor, a diferença existente entre os atos de fala comuns e os literários não é a existência ou não das coisas, ou o estatuto de veracidade dessas coisas, muito menos as alterações que os significados possam sofrer nos textos literários: a diferença é que o modo de performance e interpretação varia; é como se o leitor que lê ficção o fizesse com "atitude alterada". Cria-se, por conseguinte, nesse discurso, uma "ilusão referencial", 
instaura-se entre escritor e leitor um pacto segundo o qual o escritor está se referindo, não ao mundo real, mas à sua própria interpretação do mundo real, ou ao seu próprio mundo criado, ou a ambos.

O jogo da referenciação no discurso literário exige que o interlocutor desse discurso, isto é, o leitor, refaça suas expectativas e respostas, uma vez que o referente pode ser sempre reorientado, refocalizando e redefinindo, na progressão de cada leitura. Daí que, segundo Whiteside, um dos prazeres de ler e reler o texto literário advém de que a referência e, em decorrência, o significado na progressão de cada leitura nunca são completos.

Vale dizer que tanto no discurso ordinário quanto no literário, porém mais ainda neste do que naquele, a referência se efetiva pela contribuição dos contextos trazidos pelos leitores. Dessa forma, "a referência literária assume suas próprias implicações fenomenológicas, e a referência extratextual ou 'realidade' é substituída pelo conceito de validade" (WHITESIDE, 1987).

2 O PROCESSO DE REFERENCIAÇÃO E A CONSTRUÇÃO DOS SENTIDOS NO ROMANCE O CORONEL E O LOBISOMEM

O escritor não enuncia sua obra num contexto neutro e estável, pois pertence, ao mesmo tempo, ao campo literário e à sociedade, e não se fixa exclusivamente em nenhum deles. Uma narrativa literária opera dinamicamente com um duplo cenário enunciativo: o da história contada e o da narração dessa história. O primeiro refere-se ao ambiente da própria ficção; o segundo, à enunciação do narrador dirigida a um leitor. $\mathrm{Na}$ análise de um texto literário, a consciência dessa multiplicidade de contextos é fundamental. E a interação entre os contextos é de total relevância para a referência, a qual, constituindo um ato de fala, integra o ambiente cultural e ideológico de escritores e leitores.

O romance $O$ coronel e o lobisomem retrata a trajetória do coronel Ponciano de Azeredo Furtado, que é o protagonista da obra. O texto 
registra a autobiografia do coronel Ponciano que, ao se instituir como EU, designa a pessoa que enuncia e implica, ao mesmo tempo, um enunciado sobre esse EU. Os episódios que aparecem no romance são centrados no EU do narrador/protagonista que, assim, constitui o âmago de toda narrativa. Por ser narrado em primeira pessoa, há uma expressividade predominante do EU, que se torna evidente logo nas primeiras linhas da obra, quando fica delineada a qualificação de Ponciano para o desempenho das funções de narrador e protagonista:

A bem dizer, sou Ponciano de Azeredo Furtado, coronel de patente, do que tenho honra e faço virtude. Herdei de meu avô Simeão terras de muitas medidas, gado do mais gordo, pasto do mais fino (Ex. 3, p. 3).

Convém dizer que o romance não traz uma intriga nuclear, não se apóia em um conflito central, pois curiosamente sua unidade interior está voltada para a constituição da figura do coronel que é "um misto de D. Quixote, Narciso e D. Juan", conforme Coelho (1966, p. 340). Por meio do discurso direto e do discurso indireto, o narrador, uma vez posicionado como o centro da narrativa, coloca-se diante do outro e constrói uma imagem dotada de especificidades e valores que ele atribui a si mesmo.

O núcleo central dos acontecimentos do romance em questão é o fazer narrativo. Os acontecimentos, retratados de forma linear, obedecem à cronologia das ações, por isso os eventos são narrados conforme se sucedem na vida de Ponciano. Com certa freqüência, ele refere-se a si mesmo não com a primeira pessoa do singular, mas com a terceira. Para isso, utiliza o próprio nome no lugar do EU, numa tentativa de objetividade e de distanciamento do discurso.

Em presença de tal apelação, mais brabento apareceu a peste. Ciscava o chão de soltar terra e macega no longe de dez braças ou mais. Era trabalho de gelar qualquer cristão que não levasse o nome de Ponciano de Azevedo Furtado. Dos olhos do lobisomem, pingava labareda, em risco de contaminar de fogo o verbal adjacente. (Ex. 4, p. 179) 
Uma vez que a primeira pessoa é o lugar privilegiado da subjetividade e a terceira pessoa o da objetividade, Fiorin (2001, p. 100-101) considera a segunda como o lugar tanto da não-subjetividade quanto da não-objetividade. Então, o uso de uma pessoa com o valor de outra produz não apenas certas possibilidades de ruptura, mas ainda novos sentidos no discurso literário. Isso quer dizer que utilizar a terceira pessoa no lugar de outra é objetivar o discurso, esvaziar a pessoa, enfatizar o papel social em detrimento da individualidade.

Como nossa preocupação é com as atividades lingüísticas situadas e não com as estruturas da língua descarnadas de seus usuários, estamos tentando explicar como é possível compreender e produzir intersubjetivamente sentidos públicos por meio da atividade lingüística. Ao admitirmos que as habilidades comunicativas não são puramente lingüísticas, adotamos também a tese central de que não há relação direta e biunívoca entre linguagem e mundo, o que tem conseqüências de longo alcance para a noção de referência como um sistema de enquadre.

Assim, é na interação que emergem os sentidos no romance $O$ coronel e o lobisomem, numa espécie de ação coletiva, o que permite afirmar que as relações que possibilitam a continuidade temática e a progressão referencial no referido texto, fazendo surgir coerência e coesividade, não são propriedades intrínsecas apenas. E o texto passa a ser muito mais do que um simples continente de informações, tornandose um sistema de instruções para a ação conjunta (MARCUSCHI, 2003). É nesse contexto que a questão central dos processos referenciais deverá ser analisada. Sob esse aspecto é relevante analisar como o romance constrói seus mundos por meio da linguagem falada.

Ao referir-se a si mesmo pelo nome, Ponciano usa uma terceira pessoa com o valor de primeira. Outras vezes, ele utiliza seu sobrenome com valor de primeira pessoa do singular:

A par de que este Azeredão desejava fazer vistoria de casamento em sua pessoa, Bebé de Melo, livre dos restos da caxumba, tratou de ganhar estrada. (Ex. 5, p. 142) 
Compareci à presença de Dona Esmeraldina para lavar a testada. Eu afianço que pagou a pena ficar encaxumbado. A mulher de Nogueira, quase botou este Azevedo Furtado no colo. (Ex. 6, p. 237)

Mais de um amigo, vendo este Azeredão Furtado tão de bolsa aberta, cuidou que eu tivesse perdido as forças da cabeça e caído na demência. (Ex.7, p. 248)

Ainda percebi, no derradeiro furo das minhas forças, aquele correcorre cada vez mais lonjal - Tutu pedindo vela e Antão Pereira em choro. Um sono de paia, desses que fecham os olhos da gente com bondade, tomou conta deste Azeredão Furtado dos pastos de Santo Amaro.(Ex. 8, p. 299)

Meti a colher dos Azeredos Furtados nessa panela de bobagem. Como desembargador em presença das partes, mandei que ele largasse de lado os pormenores e entrasse no mérito da questão. (Ex. 9, p. 141)

Podemos verificar que o sujeito não é apenas enunciativo e sim também criativo e social. Assim, na ação social situada, ele instaura e diz o mundo. Como há poucos eventos concretos, a maior parte dos fatos são discursivos e, por isso, é a própria narrativa que constitui a obra, em que o narrador se preocupa mais em dar significação a seu personagem do que com o simples relato dos fatos. A esse respeito Coelho (1996, p. 343) observa que "a cada momento ele sai de si mesmo e contempla-se, admira-se como se de outro ser se tratasse. Como se o 'coronel' fosse a personalidade social, a personalidade exibida ao mundo e o 'outro', o seu êmulo, adorador e cortejador".

Entretanto, apesar de as fragilidades do coronel estarem nitidamente registradas no texto, vale dizer que em nenhum momento da obra Ponciano, que se revela um astuto explorador de circunstâncias favoráveis, dá a impressão de ser covarde. Ao final de cada episódio, o efeito de sentido instaurado é o de coragem, sentimento que salvaguarda a aparência de homem destemido.

Podemos afirmar que a qualidade mais marcante em Ponciano é a vaidade e é em função dela que surgem outros aspectos de sua personalidade. Daí a naturalidade com que a narrativa sempre gira em 
torno da pessoa do coronel. Vale lembrar que, na manipulação do relato em primeira pessoa, constantemente o narrador desenvolve certos desdobramentos, que lhe proporcionam certa liberdade para descrever as ocorrências por um ângulo que não seria possível numa visão restrita à primeira pessoa, por isso as cenas são vistas ora de dentro ora de fora do personagem-narrador, por um amálgama de planos que se constituem num todo narrativo.

Atente-se para o fato de que o leitor chega a esses significados, em grande parte, pelo trabalho de referenciação efetuado no texto. Dessa forma, ao utilizar-se da auto-representação, efetua uma auto-referência, colocando-se como uma terceira pessoa e tornando-se referente de seu próprio discurso, por meio do qual se exalta e canta suas grandezas. Nesse processo, o uso do ELE coloca o narrador como um referente fora do discurso, evidenciando-se a fragmentação do sujeito por meio da evocação da presença de um outro EU.

Uma vez que o narrador é o próprio Ponciano, ao referir-se a si mesmo por meio de substantivos próprios que designam seu nome ("Seu Ponciano", "Ponciano", "Ponciano de Azeredo Furtado"), o texto utiliza uma referência de terceira pessoa com o valor de primeira. Ao realizar a auto-referência, por meio das formas substantivadas que designam seu nome/sobrenome, Ponciano ressalta seu papel social. Nesse tipo de neutralização ocorre ainda o emprego de outros substantivos com valor de EU. Tais ocorrências podem indicar, por exemplo, graus de parentesco:

Passava semanas em velhacaria de pular muro atrás dos bicos-delacres e coleirinhos. O avô Simeão, enterrado no sem-fim dos pastos, não podia acompanhar as capetagens do neto. (Ex. 10, p. 5)

Mas foi o pai saber que o neto de Simeão estava na praça, para arrumar ligeirinho o baú e esconder a donzelice de dona Branca no fundo do sertão restinguento. (Ex. 11, p. 8)

Digo, sem ostentação, que Deus não cresceu o neto do meu avô na beira dos dois metros para que ele desperdiçasse essa grandeza toda em raiva de anão, em ódio de sujeito nascido para caber num dedal de costureira. (Ex. 12, p. 24) 
Soubesse ele, e mais Jordão Tibiriçá, que o neto do velho Simeão não levava medo do governo. (Ex. 13, p. 149)

Ponderei no mesmo ar Brincalhão:

- Ora, Dona Alvarina, quem é que vai querer um solteirão como este seu compadre? (Ex. 14, p. 71)

Juca Azevedo, sem prática de pantaneira, cuidou que o seu parente estivesse para esticar canela. trocei dele e da doença:

- Ainda vão inventar mazela capaz de jogar este seu primo no barro do cemitério. (Ex. 15, p. 89)

Mas estava escrito e estipulado que o neto de Simeão do Sobradinho não ia aproveitar as ausências do doutor. (Ex. 16, p. 236)

Bem Juquinha não acabou, já pulava eu na direção das malas e bagagens. Chamei Dona Alvarina:

- Comadre, apronte os utensílios. Vou mostrar a esses cachorros do governo quem é seu compadre Ponciano. (Ex. 17, p. 290)

Nos exemplos mencionados, Ponciano, ao apresentar seu papel social como herdeiro abastado dos Azeredo Furtado, utiliza a autorepresentação, evidenciando seu parentesco consangüíneo na condição de herdeiro por meio dos seguintes referentes: "do neto", "o neto de Simeão", "o neto de meu avô", "o neto do velho Simeão", "o neto de Simeão do Sobradinho".

Essa linhagem também é confirmada por meio do emprego de outros referentes, "o seu parente" e "este seu primo", que também marcam o referido parentesco. Além disso, há outras referências que indicam parentesco como resultado de um acordo social. Elas referemse ao papel social que Ponciano assume ao apadrinhar o filho recémnascido de Juquinha Quintanilha, com quem passa a estabelecer uma espécie de laço familiar.

Ponderei no mesmo ar brincalhão:

- Ora Dona Alvarina, quem é que vai querer um solteirão como este seu compadre?

Nos rodados do vestido da menina Isabel meu atrevimento encolhia. (Ex. 18, p. 71) 
Nos fragmentos, a seguir, Ponciano representa a si mesmo pelo emprego dos referentes de "alferes", "o capitão" e "o coronel". Nesses casos seu papel social de autoridade militar é destacado, o que vem revelar uma ascensão no posto de autoridade pela ordem com que apresenta esses referentes. A seguir, exemplos das ocorrências das patentes:

Dito isso, já largava o assunto quando, de uma cadeira, vi aquela bengala crescer e atrás dela um velhote munido da necessária licença para que $o$ alferes desagravasse o povo presente. (Ex. 19, p. 12)

Ele não conhecia o capitão. Do que eu mais apreciava e fazia alarde era da convivência com os rabos-de-saia dos palcos. (Ex. 20, p. 15) Com esses e outros galhofismos dei a ameaça de Cicarino Dantas por acabada. E mão no ombro de Dioguinho:

- Seu compadre, bala que vai matar este coronel ainda está no fabrico. (Ex. 21, p. 20)

Antão, sem coisa a responder, soltou o faro dos seus cachorros pelos escondidos, de não ficar caruru mais corriqueiro sem ser fuçado. E nada de capivara. Recriminei o boiadeiro:

- Seu Pereira. Seu Pereira! Como é que tem a ousadia de tirar da cama um coronel de patente para um rebate falso de capivara? (Ex. 22, p. 44)

De noite, em conferência de travesseiro, deliberei tomar estado. Não ia deixar que a pança crescesse, de não caber em porta, para pedir costela de moça, que nenhum pai consentia em tamanho despautério. $\mathrm{O}$ melhor era apregoar, nos pastos que o Coronel Ponciano de Azevedo Furtado andava atrás de menina donzela que quisesse tomar conta do Sobradinho. (Ex. 23, p. 64)

No abrir da noite apareceu na Rua da Jaca o tabelião Pergentino de Araújo. A par de que o coronel seu amigo andava em rixa contra doença ruim, veio em passeio de visita. (Ex. 24, p. 89)

Espalharam, mais tarde, que o coronel do sobradinho abusou e dasabusou das partes de cima da sereia, que as debaixo, escama só, nunca tiveram serventia. (Ex. 25, p. 107)

Apontei fontainha - não sou dado a esconder glória de ninguém. Além do mais, não calhava a um militar, no rigor a patente, tratar desses embonecamentos de sala e saleta. (Ex. 26, p. 200) 
Por falta de sorte, vinha subindo os degraus nessa precisa ocasião um mulatinho que ajudava Pernambuco Nogueira nas demandas do Foro. Veio saber do paradeiro de Fontainha e levou a notícia de que o coronel do Livro Verde andava rasgando dinheiro do governo, desmontado da cachola, atacado da mania de grandeza. (Ex. 27, p. 250)

A auto-referência é realizada, finalmente, por meio da patente de coronel que vem enaltecer a imagem de Ponciano, e que o coloca acima dos outros, como autoridade militar. Convém dizer que esse é o papel que Ponciano mais gosta de representar em toda obra, em que ele é sempre "o coronel", aquele que se apresenta como um ser superior aos demais. Novamente, o texto enfatiza a condição de herdeiro abastado de Ponciano, dono de muitas terras e com muito gado no pasto, ao fazer referência a ele como "o patrão", colocando-o no comando de bens materiais e detentor do poder.

As formas perifrásticas de efeito metonímico ${ }^{4}$ e de efeito metafórico surgem também produzindo determinados efeitos de sentido no processo de auto-referenciação em questão, a saber:

O que Dona Bidu queria é que eu forçasse noite alta, a janela da casa e de lá extraísse a menina em garupa de cavalo. Como não caí na armadilha, desandou, fui sabedor mais tarde, a dizer que a filha dela não casava com o barbaça do Sobradinho nem por ouro, nem por prata. (Ex. 33, p. 164)

Estranhei tal visita, uma vez que fazia Baltazar da Cunha em MataCavalo, no trabalho de sua 'engenharia. Sem cuidar de que eu estivesse presente, perguntou em que buraco podia ser encontrado o capitão-do-mato patrão dele, um tal de Ponciano de Azevedo Furtado? (Ex. 34, p. 257)

Desde que escorreguei no comércio de compra e venda, fui outro. Cada dia que passava, mais o coronel do mato vinha a furo, destrambelhado e ferino. (Ex. 35, p. 286)

Baseando-nos no pressuposto de que a referenciação constitui uma atividade discursiva (MARCusCHI, 2002), pressuposto esse que implica 
uma visão não-referencial da língua e da linguagem, e ainda, no que vimos nos exemplos citados, somos levados a postular uma instabilidade das relações entre as palavras e a coisas. Essa posição é também defendida por Mondada \& Dubois (1995). Isso porque referência é considerada como o resultado da operação que realizamos quando, para designar, representar ou sugerir algo, utilizamos um termo ou criamos uma situação discursiva referencial com essa finalidade: as entidades designadas são vistas como objetos de discurso e não como objetos de mundo. Essa acepção implica admitir que os objetos de discurso são dinâmicos, isto é, uma vez introduzidos, podem ser modificados, desativados, reativados, transformados, recategorizados, construindo-se e reconstruindo-se o sentido, no curso da progressão textual. É o que tentamos mostrar com os procedimentos de auto-referenciação, a partir da linguagem oral desse romance literário.

Por outro lado, a interpretação de uma expressão anafórica, nominal ou pronominal, consiste em estabelecer uma ligação com algum tipo de informação que se encontra na memória discursiva. Ao usar e manipular uma forma simbólica, usamos e manipulamos tanto o conteúdo como a estrutura dessa forma. Conseqüentemente, também manipulamos a estrutura da realidade de modo significativo. Nesse sentido, a descrição definida é um conceito fecundo para o nosso trabalho pelo fato de que o locutor opera uma seleção, dentre as propriedades atribuíveis a um referente, daquela que, em dada situação discursiva, é relevante para a viabilização de seu projeto de dizer. No caso de nossos dados, o projeto de enaltecer a imagem de Ponciano.

A escolha de determinada descrição definida traz ao leitor informações importantes sobre as opiniões, crenças e atitudes do produtor do texto, auxiliando-o na construção do sentido. Isso pode ser verificado nos exemplos articulados, em que a descrição feita tem o objetivo de dar a conhecer ao interlocutor a trajetória de vida do coronel, sempre às voltas com os mais diferentes problemas. Para isso, o discurso literário utiliza expressões nominais, que fazem referência a EU, isto é, também 
empregadas para expressar um grau explícito de superioridade em construções com substantivos + desinências de aumentativo, de forma a construir uma imagem positiva do coronel, do homem, até então mais ligado à força física. É o que observamos no exemplo:

Fui receber Dona Esmeraldina no começo da escada e até ajudei seu pezinho de palma a vencer o último degrau. Só de gozar aquele riso de covinha no rosto fiquei mudado. Nem parecia o coronelão desmontador de móveis e utensílios. (Ex. 36, p. 259-260)

As formas nominais referenciais, em grande parte, respondem, simultaneamente, pelos dois grandes processos de construção textual: retroação e prospecção (KocH, 2003). Em termos de remissão a elementos anteriormente apresentados na narrativa ou sugeridos pelo co-texto precedente, elas possibilitam a sua (re)ativação na memória do leitor, ou seja, a focalização na memória operacional deste. Nos exemplos 34 e 35, as formas nominais "capitão do mato" e "coronel do mato" surgem para remeter o texto à imagem do homem em ascensão, numa menção de Ponciano às suas patentes de capitão e de coronel do sertão, em relação ao texto precedente, conforme exemplo 32 ("O pior foi engambelar Francisquinha, que não queria deixar seu menino seguir viagem. Inventei imposição do governo, dever do meu ofício de coronel"), em que a imagem anterior de menino, de filho já tinha sido mobilizada.

Ao operarem uma refocalização do referente, as informações têm função predicativa, isto é, elas são veiculadoras tanto de informação dada ("um menino", "meu ofício de coronel"), como de informação nova (coronel do mato). Nessa direção, as formas remissivas nominais têm uma função organizacional importante, uma vez que sinalizam que o autor do texto está passando a um estágio seguinte de sua formulação, fechando o estágio anterior por meio de uma outra forma nominal. Assim, desempenham papel de relevância na introdução, mudança ou desvio de tópico, bem como na ligação entre tópicos. Em outros termos, elas introduzem mudanças ou desvios do tópico, preservando, contudo, a continuidade tópica, ao alocarem a informação nova ("capitão do mato") 
dentro do quadro da informação dada ("um menino", "meu ofício de coronel"), realizando os movimentos de construção textual de retroação e prospecção.

Um caso diferente é o uso de um termo em lugar de outro, com o qual mantém uma relação de efeito metonímico, conforme pode ser observado:

$\mathrm{Na}$ esperança de descontar os desmandos das águas nos ganhos do comércio, abri as comportas da especulação. Em menos de uma quinzena comprei açúcar em grosso, mais de um armazém de mascavo e cristal. A barba do coronel não saía das casas de negócio da Rua do Rosário, em visita de esperteza. (Ex. 37, p. 262)

O banhudo Macedo Costa, montado na jurisprudência de Nogueira, cresceu em ofensa: Não quero acordo, não quero nada. Era desaforo demais para a patente de um coronel. Dedo no focinho dele, mandei que tivesse respeito, que não estava eu no escritório para aturar maleducados e sim em dever de cortesia. (Ex. 38, p. 276)

Em verdade, a pendenga andou e inchou. Nas mesas dos escrivães e doutores pegou papel de muitos rabiscos, engordou nos embargos e pareceres. Como nos dias de minha guerra contra Dona Mesquita, o charuto de Ponciano não saía dos corredores da justiça. (Ex. 39, p. 279)

Nesses fragmentos, a auto-referenciação realizada por meio de referentes como "a barba do coronel", "a patente de um coronel" e o "charuto de Ponciano" enfatiza atributos com os quais Ponciano identifica sua personalidade: a barba, que lhe confere a imagem de homem másculo; a patente que lhe garante a autoridade de militar; e o charuto, que confirma seu status social.

De modo geral, a recategorização de referentes envolve seleções de natureza semântica ou cognitiva e se baseia em inferenciações fundadas em índices lexicais contextualizados. Esses índices são os antecedentes ou fontes do elemento remissivo, que contribui para a continuidade textual. É nessa ótica que os referentes textuais são tomados como objetos de discurso. Especificamente, nos nossos dados, eles se 
constituem no discurso mesmo quando estão ancorados numa realidade extratextual, de modo que a linguagem oral não cria o discurso literário, mas o constitui de uma determinada forma e num arranjo específico.

\section{CONSIDERAÇÕES FINAIS}

A referenciação textual, instaurando e mantendo os objetos de discurso, pode ser vista como o suporte primeiro da construção do sentido, na manifestação da competência comunicativa do locutor. $\mathrm{O}$ que se verifica é que, partindo de uma visão da língua em função, pode-se discutir com proveito a questão da introdução e da manutenção de referentes como objetos de discurso, um processo que envolve a interação, e, conseqüentemente, os propósitos do locutor quanto à existência dos referentes no universo do discurso negociado entre os participantes da interlocução. Verifica-se que, envolvida nos propósitos da interação, pode ser discutida, nessa linha de reflexão, a utilização que o locutor faz dos processos de categorizar (e recategorizar), para manipulação da direção do enunciado. No entanto, consideramos que, no caso específico deste estudo, a recategorização pode ser um fenômeno muito diversificado e, por vezes, envolve aspectos de remissão com rotulações bastante complexas, elaboradas com estratégias muito diversificadas.

É certo que o locutor, em função de fatores intra ou extradiscursivos, pode sempre decidir pela homologação ou não, por meio de suas escolhas lexicais, de uma transformação ou mudança de estado constatada ou predicada. Simetricamente, ele pode também alterar a categorização de um objeto independentemente de toda e qualquer transformação asseverada a respeito deste.

Sabemos que uma referenciação textual é bem sucedida quando o interlocutor consegue identificar o referente do discurso na medida em que essa operação lhe é solicitada; essa identificação acontece quando o locutor a deixou acessível. Com isso, a identificabilidade e a acessibilidade estão estreitamente ligadas à distribuição de informação, a partir 
da distribuição do dado e do novo no discurso. Vale retomar aqui a afirmação de Chafe (1996) de que ambas as categorias pressupõem o processo de inferência, mas na acessibilidade a inferência é mais direta e imediata, não se limitando a pessoas, objetos e abstrações, mas estendendo-se a eventos e estados. Nos nossos dados, evidenciamos a identificabilidade, a partir do julgamento, pelo locutor, de que o conhecimento do referente a que se remete já é compartilhado (direta ou indiretamente) com o interlocutor.

Isso vem assinalar que a imagem que o discurso literário constrói, por meio da linguagem oral, implica conhecimentos partilhados, entre os interlocutores, nesse caso o da imagem do coronel do sertão, o da imagem do poder etc. A escolha, pelo locutor, de uma linguagem com esse rigor de categorização leva-nos a considerar que todos os referentes compartilhados por ele e pelo interlocutor se reduzam ao que está em evidência: a valorização da imagem de Ponciano. Com isso, surge o julgamento, pelo locutor, de que esse referente particular é o exemplar mais saliente da categoria, dentro daquele contexto, por exemplo, "coronelão desmontador", "o neto de Simeão do Sobradinho", o coronel de patente" etc.

Este estudo buscou obter uma compreensão do discurso do coronel Ponciano de Azeredo Furtado, narrador-protagonista de $O$ coronel e $O$ lobisomem, de José Cândido de Carvalho, em que se pode vislumbrar uma natureza discursiva múltipla. Ao exercer as funções de narrador e de protagonista, Ponciano detém a posse da palavra, expressa por meio de enunciados em que predomina a subjetividade, num discurso que carrega as formas que reportam ao EU. Ponciano é um narrador egocentrado que se instaura como sujeito da enunciação e relata os fatos a seu modo. Por isso quase toda unidade do romance está voltada para a constituição de sua imagem: ao utilizar o discurso em primeira pessoa, apresenta-se como ser dotado de grandes qualidades.

Ao mobilizar a linguagem oral para influenciar seu interlocutor, o locutor subjetiviza seu próprio enunciado com o emprego de formas lingüísticas que marcam seu posicionamento singular no discurso literário, 
por meio de categorias que nos levam a refletir sobre o processo de referencialização em pauta.

Ressalte-se que, no desenvolvimento do relato de primeira pessoa, Ponciano realiza certos desdobramentos que lhe possibilitam empregar a terceira pessoa no lugar da primeira, isto é, subverter a pessoa, numa auto-referenciação. Por meio deles, o locutor se posiciona como uma terceira pessoa, tornando-se o referente de seu próprio discurso em ocorrências que tendem a ressaltar seu papel social em detrimento de toda subjetividade e comprometimento com o seu discurso.

Tais desdobramentos constroem a auto-representação do próprio Ponciano e lhe possibilitam descrever-se da perspectiva que ele pretende que os outros o vejam. Observados os casos em que ocorrem tais desdobramentos, verificamos que Ponciano realiza a auto-referência para enaltecer sua imagem ora como herdeiro abastado dos Azeredo Furtado, ora como autoridade militar que a patente de coronel the proporciona. Dessa forma, o referente empregado em cada ocorrência atribui o status social almejado pelo discurso de Ponciano.

Um outro ponto a ser destacado é que as expressões definidas, no romance estudado, apresentam especificidades que podem ser uma constante do discurso literário: a introdução sistemática de referentes novos por meio de expressões definidas, como se o leitor fosse instigado a entrar no mundo ficcional e se visse obrigado a aceitar o cenário apresentado como algo dado ou como algo que integrasse um conhecimento partilhado. No entanto, essa hipótese precisa ser ainda testada em outro corpus representativo, considerando sempre que o discurso literário e o discurso ordinário possuem formas distintas de se organizarem.

\section{REFERENTIATION: A STUDY OF ASPECTS OF ORALITY IN THE LITERARY DISCOURSE}

\section{AbSTRACT}

Our study about oral language involved in the interaction objectives, by the literary discourse, discusses the use that the speaker makes about the 
categorization process (and the recategorization as well), to manipulate the enunciation direction from the presupposition that the referentiation constitutes a discursive activity.

KEY wORDS: Reference, textual production, literature, oral language.

\section{NotAS}

1. Personagem-narrador do romance $O$ coronel e o lobisomem que procura construir, todo o tempo, a imagem ideal do homem forte e poderoso do sertão.

2. O termo "filigranas", utilizado por Maria do Rosário V. Gregolin (2000, p. 9), e que está associado à figura da filigrana (obra de ourivesaria formada de fios de ouro ou prata, delicadamente entrelaçados e soldados), são os fios significativos, fios de sentido que se entrelaçam e se soldam e constituem a nossa percepção presente.

3. Os grifos observados em todos os trechos dos romances citados são nossos.

4. São os termos relacionados a um aspecto físico de alguém (parte) e usados em substituição de outros que fazem referência a esse alguém (todo); como exemplo temos "o barbaça do Sobradinho".

\section{REFERÊNCIAS}

ApothÉLOZ, D.; ReICHLER-BÉGUeLIN, M. Construction de la reference et stratégies de désignation. TRANEL (Travaux Neuchâtelois de Linguistique) 23: Du syntagame nominal aux objets-de-discours, p. 227-271, 1995.

Bakhtin, M. Marxismo e filosofia da linguagem. 4. ed. São Paulo: Hucitec, 1988.

Benveniste, E. Problemas de lingüistica geral II. Campinas: Pontes, 1989.

Carvalho, J. C. O coronel e o lobisomem. 32. ed. Rio de Janeiro: José Olympio, 1982.

Chafe, W. Inferring identifiability and accessibility. In: Fretheim, T.; Gundel, J. K. Reference and referent accessibility. Amsterdam: John Benjamins, 1996. p. $37-46$. 
Coelho, N. N. O coronel e o lobisomem. O ensino de literatura. São Paulo: FTD, 1966.

Fiorin, J. L. As astúcias da enunciação: as categorias de pessoa, espaço e tempo. São Paulo: Ática, 2001.

Gregolin, M. R. V. Filigranas do discurso: as vozes da história. Araraquara: FCL/Laboratório Editora/Unesp; São Paulo: Cultura Acadêmica, 2000.

Косн, I. V. Desvendando os segredos do texto. São Paulo: Cortez, 2003.

Lyons, J. Semantics. Cambridge: Cambridge University Press, 1977.

MARCUSCHI, L. A. Estratégias de referenciação e progressão referencial na língua falada. In: Abaurre, M. B; Rodrigues, A. C. S. (Orgs.). Gramática do Português falado, v. VIII, Campinas: Editora da Unicamp, 2002. p. 31-58.

. Atividades de referenciação no processo de produção textual e o ensino de língua. In: Silva, D. G.; Lara, G. P.; Menegazzo, M. A. (Orgs.). Estudos de linguagem. Campo Grande: Editora da UFMS, 2003.

MondadA, L.; Dubois, D. Construction des objets de discours et categorisation: une approche des processus de référenciation. In: BerRendoner, A.; M-J Reichler-Beguelin (Eds.). Du syntagme nominal aux-objets-de-discours: SN complexes, nominalisations, anaphores. Neuchatel: Institute de Linguistique de L'Université de Neuchatel, 1995. p. 273-302.

Neves, M. H. M. A referenciação e a constituição do texto: reflexões no uso da língua portuguesa. Araraquara, 2000. Mimeografado.

Whiteside, A. Conclusion: theories of reference. In: Whiteside, A.; IsSACHAROFF, M. On referring in literature. Indianapolis: Indiana University Press, 1987. 